\title{
Association between treatment-related lymphopenia and survival in glioblastoma patients following postoperative chemoradiotherapy
}

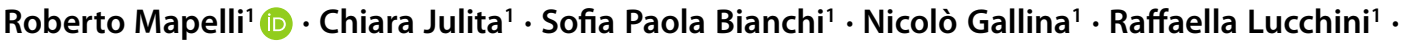

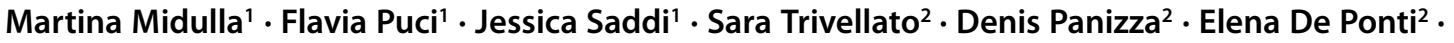 \\ Stefano Arcangeli ${ }^{1}$
}

Received: 11 January 2021 / Accepted: 17 August 2021 / Published online: 6 October 2021

(c) The Author(s) 2021

\begin{abstract}
Purpose Our study investigated the association between treatment-related lymphopenia and overall survival (OS) in a series of glioblastoma (GBM) patients. We also explored clinical and dosimetric predictors of lymphocytes depletion. Methods Between 2015 and 2019, 64 patients were treated at the same institution with postoperative chemoradiotherapy. Peripheral lymphocyte count (PLC) data and dose-volume histogram parameters were collected. Radiotherapy (RT) schedule consisted in standard total dose of $60 \mathrm{~Gy}$ in 30 daily fractions, with concomitant and adjuvant temozolomide (TMZ). Posttreatment acute absolute lymphopenia (nadir AAL) was calculated as a PLC lower than $1.0 \times 10^{3} / \mathrm{mm}^{3}$. Acute relative lymphopenia (ARL) was expressed by the nadir-PLC/baseline-PLC ratio $<0.5$. Nadir-PLC was the lowest PLC registered between the end of RT and the first month of follow-up. Survival rates were estimated with Kaplan-Meier curves. Clinical and dosimetric variables related to AAL/ARL and OS were identified by univariate and multivariate analyses.

Results A total of 57 patients were eligible and included in the analyses. The median PLC was significantly decreased following chemoradiotherapy $\left(2180 / \mathrm{mm}^{3} \mathrm{vs} 900 / \mathrm{mm}^{3}\right)$. Median OS was 16 months (range 5-55 months), with no significant difference between patients who developed nadir AAL and those who did not (16 months vs 16.5 months; $p=0.304$ ). When considering ARL vs non-ARL, median OS was 14 months vs 26 months $(p=0.013)$, respectively. In multivariate Cox regression only age, sex, extent of surgery, access to adjuvant chemotherapy and brain D98\% were independently associated with OS.

Conclusion Although iatrogenic immunosuppression could be associated with inferior clinical outcomes, our data show that treatment-related lymphopenia does not adversely affect GBM survival. Prospective studies are required to confirm these findings.
\end{abstract}

Keywords Lymphopenia $\cdot$ Immunosuppression $\cdot$ Glioblastoma $\cdot$ Radiotherapy $\cdot$ Temozolomide

\section{Introduction}

Radiation-induced lymphopenia has been associated with poor survival in several solid tumors such as, esophageal

Availability of data and material The datasets generated during and/or analyzed during the current study are available from the corresponding author on reasonable request.

Roberto Mapelli

r.mapelli.95@gmail.com,r.mapelli4@campus.unimib.it

1 Department of Radiation Oncology, University of Milan Bicocca and San Gerardo Hospital, Monza, Italy

2 Department of Medical Physics, San Gerardo Hospital, Monza, Italy
[1], lung [2-4], pancreatic [5] and cervical cancers [6, 7]. Lymphocytes are among the most radiosensitive cells in the body with a D10 (dose to reduce the total amount of surviving cells to $10 \%$ of the initial value) of around 3 Gray (Gy) only $[8,9]$. It is then possible that even a low dose given in short daily intervals may interfere with the priming process of $\mathrm{T}$ lymphocytes and their memory functions, resulting in an immunosuppressive status potentially related to a more rapid disease progression and shorter survival.

Concurrent radiation therapy (RT) and temozolomide (TMZ) followed by adjuvant monthly TMZ after surgery remains a mainstay treatment modality for most patients with glioblastoma (GBM) [10].

These multiple therapeutic interventions, however, cause up to $40 \%$ of high-grade glioma patients to develop severe 
lymphopenia (grade 3-4 toxicity) within 2 months after course initiation [11]. Such a decline of the immune system, even enhanced by the combination with steroids, might result in an increased susceptibility to opportunistic infections such as pneumocystis pneumonia [12, 13] and a reactivation of cytomegalovirus, as a rare complication [14, 15]. But, more importantly, it might turn out to be associated with worse survival. A mathematical model used to estimate the RT exposure of circulating lymphocytes during RT to the brain has shown that over $95 \%$ of circulating cells received a lymphotoxic dose after a conventional course of 30 daily fractions of $2 \mathrm{~Gy}$ [16].

While initial preclinical experiences have revealed promising results with a wide array of immune therapies that have generated hopes for the treatment of this fatal disease $[17,18]$, current clinical practice is still based on the combination of RT and TMZ that can lead to significant lymphopenia in high-grade glioma patients [11, 19-21], thus negatively affecting patients' outcomes.

The aim of this study is to investigate the correlation of lymphocyte depletion during concurrent RT/TMZ with outcomes in a cohort of patients affected by GBM, and to examine the clinical and dosimetric factors that might predict the development of acute severe lymphopenia.

\section{Materials and methods}

\section{Patient population}

Data of 64 patients with newly diagnosed World Health Organization (WHO) grades IV glioma treated postoperatively with RT and concurrent TMZ at a single institution, between March 2015 and July 2019, were retrospectively reviewed. Patients were excluded from the analysis in case of (a) previous irradiation to head and neck region; (b) open or stereotactic biopsy only; c) dose to the tumor area lower than $54 \mathrm{~Gy}$; d) inaccessible RT dosimetric data and/or lack of information on lymphocyte count; e) follow-up shorter than 12 months. A total of 57 patients were eligible and included in the analyses; 7 patients were excluded because of lack of data on lymphocyte count.

The research was carried out according to the principles set out in the Declaration of Helsinki 1964 and all subsequent revisions. Informed consent was obtained from all individual participants and this study was reviewed and approved by the Institutional Review Board.

\section{Radiotherapy and chemotherapy}

All patients were carefully immobilized before RT treatment with a thermoplastic head mask. Treatment simulation consisted of a CT (Computed Tomography) scan without contrast. Then, the CT images were coregistered with postoperative contrast-enhanced T1 MRI (Magnetic Resonance Imaging) sequences.

Gross tumor volume (GTV) was defined as the surgical cavity plus any residual contrast enhancement on postoperative T1 sequences. T2 FLAIR sequences were used to include edema, if deemed appropriate. A variable expansion of GTV ranging from 1 to $1.5 \mathrm{~cm}$ was performed in order to obtain the clinical target volume (CTV), according to patient's anatomy. CTV was further expanded by $3-5 \mathrm{~mm}$ to generate a planning target volume (PTV) to account for any set-up and movement errors. Organs-at-risk (OARs) constraints were the following: maximum doses to the brainstem, optic nerves and optic chiasm $\leq 54 \mathrm{~Gy}$; spinal cord $\leq 45$ Gy; lens $\leq 6$ Gy [22].

For 52 patients, the RT course consisted in 3D-CRT (3D Conformal Radiation Therapy) with 6 or $15 \mathrm{MV}$ photons. Five patients received volumetric modulated arc therapy (VMAT) with 6 megavoltage photons. In all, 56 patients received a total radiation dose of $60 \mathrm{~Gy}$, administered in 2.0 Gy daily fractions, 5 times per week. In a single case, the total dose achieved was 54 Gy in 27 fractions.

All patients were evaluated by a medical oncologist and received daily $\mathrm{TMZ}\left(75 \mathrm{mg} / \mathrm{m}^{2}\right)$ for 6 consecutive weeks, beginning at the start of RT. After a 4-week break, patients received adjuvant $\mathrm{TMZ}$ at $150-200 \mathrm{mg} / \mathrm{m}^{2}$ for 5 consecutive days, repeated every 28 days for a maximum of 6 cycles.

\section{Lymphocyte evaluation}

Baseline data were collected in a range between the first day of RT and 1 month before treatment beginning. Routine blood tests were obtained weekly during RT and subsequently repeated immediately at the end of RT and within 1, 6 and 12 months after treatment conclusion. The peripheral lymphocyte counts (PLCs) were measured with an automated analyzer system. Lymphopenia was graded according to the Common Terminology Criteria for Adverse Events version 5.0 (CTCAE v5.0).

\section{Dose-volume histogram parameters}

Whole brain (WB), GTV, CTV, PTV and OARs were delineated by an expert radiation oncologist. The hypothalamic region (HR) was retrospectively delineated by an experienced neuroradiologist who was blinded to the patients' clinical history.

The WB was contoured from the top of the skull to the foramen magnum.

Dose distributions were calculated with Monaco HD (Elekta AB, Stockholm, Sweden) treatment planning system (TPS) in 5 patients and Oncentra MasterPlan TPS (Elekta AB, Stockholm, Sweden) in 52 patients. Data about 
Table 1 Clinical, biological and dosimetric features of the studied population

\begin{tabular}{|c|c|}
\hline Features & \\
\hline Number of patients & 57 \\
\hline \multicolumn{2}{|l|}{ Clinical characteristics } \\
\hline Sex male $(\%)$ & $31(54.4 \%)$ \\
\hline $\mathrm{Age}^{\mathrm{a}}$ & $61.0(53.0-68.0)$ \\
\hline Macroscopic radical surgery $(\%)$ & $16(28.1 \%)$ \\
\hline $\begin{array}{l}\text { Time between surgery and } \mathrm{RT} \geq 6 \text { weeks } \\
(\%)\end{array}$ & $49(86.0 \%)$ \\
\hline KPS at 1 st visit ${ }^{\mathrm{a}}$ & $80(70-80)$ \\
\hline Time of FUP (months) ${ }^{\mathrm{a}}$ & $16.7(12.7-28.8)$ \\
\hline $\begin{array}{l}\text { Steroid dose at } 1 \text { month of } \\
\text { FUP } \geq 4 \mathrm{mg} / \text { day }(\%)\end{array}$ & $29(50.9 \%)$ \\
\hline CT pre-RT $(\%)$ & $34(59.6 \%)$ \\
\hline CT/RT concomitant $(\%)$ & $57(100 \%)$ \\
\hline Adjuvant CT (\%) & $49(86.0 \%)$ \\
\hline Concomitant $\mathrm{CT}$ interrupted & $6(10.5 \%)$ \\
\hline \multicolumn{2}{|l|}{ Pathological characteristics } \\
\hline Grade IV WHO & $57(100 \%)$ \\
\hline \multicolumn{2}{|l|}{ IDH status } \\
\hline Mutated (\%) & $1(1.8 \%)$ \\
\hline Non-mutated $(\%)$ & $48(14.0 \%)$ \\
\hline Unknown (\%) & $8(17.2 \%)$ \\
\hline \multicolumn{2}{|l|}{ MGMT status } \\
\hline Hypermethylated (\%) & $22(38.6 \%)$ \\
\hline Non-hypermethylated (\%) & $20(35.1 \%)$ \\
\hline Unknown (\%) & $15(26.3 \%)$ \\
\hline \multicolumn{2}{|l|}{ Tumor location } \\
\hline Frontal lobe $(\%)$ & $16(28.1 \%)$ \\
\hline Parietal lobe $(\%)$ & $5(8.8 \%)$ \\
\hline Temporal lobe $(\%)$ & $26(45.6 \%)$ \\
\hline Occipital lobe (\%) & $7(12.3 \%)$ \\
\hline Corpus callosum—fornix (\%) & $2(3.5 \%)$ \\
\hline Cerebellum (\%) & $1(1.8 \%)$ \\
\hline \multicolumn{2}{|l|}{ Lymphocyte count } \\
\hline PLC pre-RT $^{\mathrm{a}}$ & $2180(1540-2710)$ \\
\hline PLC nadir ${ }^{\mathrm{a}}$ & $900(730-1450)$ \\
\hline PLC 1-6 months FUP & $970(730-1400)$ \\
\hline PLC 6-12 months FUP & $1470(1100-1650)$ \\
\hline ARL nadir $(\%)$ & $29(50.9 \%)$ \\
\hline \multicolumn{2}{|l|}{ Dosimetric characteristics } \\
\hline VMAT $(\%)$ & $5(8.8 \%)$ \\
\hline GTV $^{\mathrm{a}}$ & $64.5 \mathrm{~cm}^{3}(41.6-91.7)$ \\
\hline $\mathrm{CTV}^{\mathrm{a}}$ & $\begin{array}{l}143.0 \mathrm{~cm}^{3} \\
(105.6-161.5)\end{array}$ \\
\hline PTV $^{\mathrm{a}}$ & $\begin{array}{l}233.2 \mathrm{~cm}^{3} \\
(174.0-259.6)\end{array}$ \\
\hline \multicolumn{2}{|l|}{$P T V$} \\
\hline Dmean $^{\mathrm{a}}$ & $60.4 \mathrm{~Gy}(60.1-60.7)$ \\
\hline D98\% ${ }^{\mathrm{a}}$ & 57.5 Gy $(56.0-58.0)$ \\
\hline D95\% ${ }^{\mathrm{a}}$ & $58.2 \mathrm{~Gy}(57.5-58.6)$ \\
\hline
\end{tabular}

Table 1 (Continued)

\begin{tabular}{|c|c|}
\hline Features & \\
\hline \multicolumn{2}{|l|}{ Brainstem } \\
\hline $\mathrm{D} 50 \%^{\mathrm{a}}$ & 22.3 Gy (5.9-27.7) \\
\hline $\mathrm{V} 50^{\mathrm{a}}$ & $8.9 \%(0.63-15.9)$ \\
\hline $\mathrm{D} 2 \%^{\mathrm{a}}$ & 56.7 Gy (41.9-58.6) \\
\hline \multicolumn{2}{|l|}{ Chiasm } \\
\hline $\mathrm{D} 2 \%^{\mathrm{a}}$ & 30.4 Gy $(13.0-54.9)$ \\
\hline \multicolumn{2}{|l|}{ Brain } \\
\hline $\mathrm{V} 50^{\mathrm{a}}$ & $22.4 \%(18.3-28.9)$ \\
\hline Dmean $^{\mathrm{a}}$ & $25.2 \mathrm{~Gy}(21.4-29.1)$ \\
\hline $\mathrm{D} 98 \%{ }^{\mathrm{a}}$ & $1.2 \mathrm{~Gy}(0.8-1.4)$ \\
\hline $\mathrm{D} 2 \%^{\mathrm{a}}$ & 61.8 Gy (61.4-62.3) \\
\hline \multicolumn{2}{|c|}{ Hypothalamus } \\
\hline Volume $^{\mathrm{a}}$ & $7.7 \mathrm{~cm}^{3}(6.8-8.9)$ \\
\hline $\mathrm{D} 98 \%{ }^{\mathrm{a}}$ & 16.9 Gy (3.9-24.4) \\
\hline $\mathrm{D} 2 \%^{\mathrm{a}}$ & $55.3 \mathrm{~Gy}(30.3-58.7)$ \\
\hline $\mathrm{D} 50 \%^{\mathrm{a}}$ & $25.9 \mathrm{~Gy}(14.0-38.3)$ \\
\hline $\operatorname{Dmin}^{\mathrm{a}}$ & 13.2 Gy (3.2-23.1) \\
\hline $\operatorname{Dmax}^{\mathrm{a}}$ & $57.9 \mathrm{~Gy}(39.2-59.5)$ \\
\hline Dmean $^{\mathrm{a}}$ & 28.8 Gy (18.6-41.3) \\
\hline
\end{tabular}

$R T$ radiotherapy, $C T$ chemotherapy, FUP follow-up, KPS Karnofsky performance status, MGMT O6-methylguanine-DNA-methyltransferase, $I D H$ isocitrate dehydrogenase, $P L C$ peripheral lymphocyte count, $A R L$ acute relative lymphopenia, VMAT volumetric modulated arc therapy, GTV gross tumor volume, $C T V$ clinical target volume, $P T V$ planning target volume, Dmax maximal dose, Dmean mean dose, Dmin minimal dose, $D 98 \%$ dose administered to $98 \%$ of volume, $D 95 \%$ dose administered to $95 \%$ of volume, $D 50 \%$ dose administered to $50 \%$ of volume, $D 2 \%$ dose administered to $2 \%$ of volume, $V 50$ volume that received $50 \mathrm{~Gy}, \mathrm{~cm}^{3}$ cubic centimeter, Gy Gray ${ }^{a}$ Median value (I-III quartile)

the volumetric extension of GTV, CTV, PTV, HR and WB were collected. The dosimetric parameters included: dose covering 98\% (D98\%) and 2\% (D2\%) of brain volume and mean dose (Dmean) brain; D98\%, D95\% and Dmean PTV; D2\% and D50\% brainstem; D2\% optic chiasm. The following parameters were collected for the hypothalamus, although they were not used for plan evaluation: D98\%, D2\%, D50\%, minimal dose (Dmin), maximal dose (Dmax) and Dmean.

\section{Follow-up and endpoints}

After treatment's completion, each patient was routinely followed at 3-month intervals.

The primary endpoints were acute absolute lymphopenia (AAL) and acute relative lymphopenia (ARL), while the secondary endpoint was overall survival (OS). AAL was determined as a nadir-PLC below 1000 cells $/ \mathrm{mm}^{3}$, with 4 grades of severity according to CTCAE v5.0. Namely, grade $1(\mathrm{G} 1)$ corresponded to a PLC $=1000-800$ cells $/ \mathrm{mm}^{3}$; $\mathrm{G} 2=800-500$ cells $/ \mathrm{mm}^{3} ; \quad \mathrm{G} 3=500-200 \quad$ cells $/ \mathrm{mm}^{3} ;$ 
$\mathrm{G} 4<200$ cells $/ \mathrm{mm}^{3}$. ARL was defined as the nadir-PLC/ baseline-PLC ratio $<0.50$. Nadir-PLC represented the lowest value of circulating lymphocytes registered within the first month of follow-up (FUP) after RT completion. OS was determined from the date of diagnosis until death from any cause; those patients alive at the time of last follow-up (7 October 2020) were censored.

\section{Statistical analysis}

Patient baseline characteristics were summarized using descriptive statistics, and the difference between lymphopenia groups were compared using Wilcoxon test for continuous variables and Fisher exact test for categorical variables. Differences in PLCs were studied with the analysis of variance (ANOVA). Survival probability was estimated using the Kaplan-Meier method and compared between groups through log-rank statistics. A univariate Cox's regression model was used to assess an association between potential prognostic factors and OS. To assess whether lymphopenia was an independent predictor of survival, a multivariate Cox's regression model was constructed using other prognostic factors that had attained a $p$-value less than 0.05 in the univariate analysis. All analyses were two-sided, and significance was set at a $p$-value of 0.05. Stata software 9.0 (Stata Corporation, College Station, TX, USA) was used to perform statistical analysis.

a

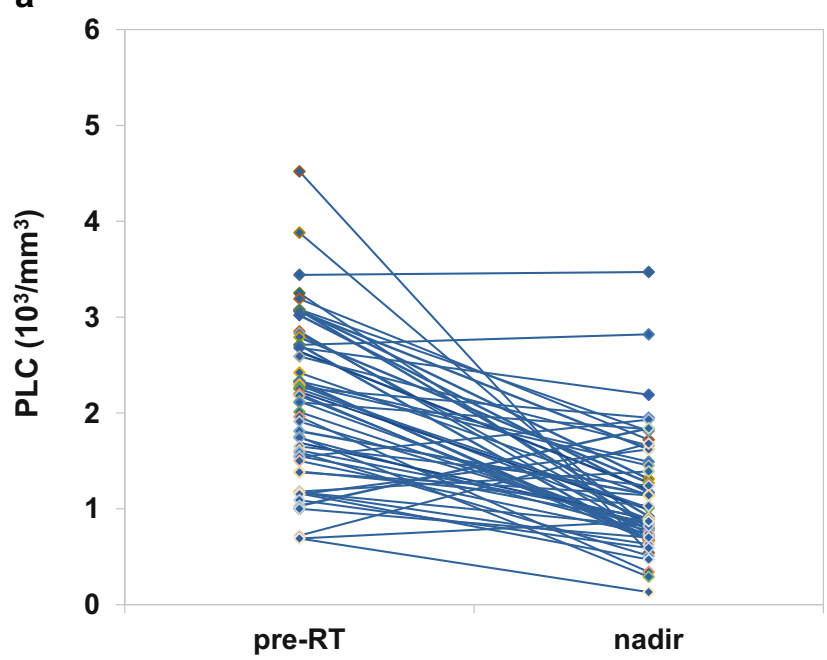

\section{Results}

\section{Basic characteristics}

All 57 patients included in the study were affected by WHO grade IV glioma (Table 1$)$. Six $(10.5 \%, 6 / 57)$ had to withdraw TMZ before the end of treatment due to development of grade 1-2 acute thrombocytopenia, with a mean platelet count of $71,800 / \mathrm{mm}^{3}$. Two patients experienced grade 1 neutropenia (neutrophils $=1500-2000 / \mathrm{mm}^{3}$ ), as well. In $49(86.0 \%, 49 / 57)$ cases, at least a cycle of adjuvant TMZ was administered. Dexamethasone was administered in 11 $(19.3 \%, 11 / 57)$ patients since the beginning of RT, at a median dose of $4 \mathrm{mg} /$ day (range: $0-8 \mathrm{mg} /$ day). By the end of RT, 45 patients $(78.9 \%, 45 / 57)$ received dexamethasone at a median dose of $4 \mathrm{mg} /$ day (range: $0-16 \mathrm{mg} /$ day). Subsequently, steroids use decreased within 1 year of follow-up (Online Resource 1).

During the period of observation, PLC underwent a marked reduction, with a median nadir of 900 cells $/ \mathrm{mm}^{3}$ (range 130-3470 cells $/ \mathrm{mm}^{3}$ ). The median baseline count was 2180 cells $/ \mathrm{mm}^{3}$ with an interval ranging from 690 to 4520 cells $/ \mathrm{mm}^{3}$. The reduction was highly significant at ANOVA test ( $p$-value $<0.001)$.

Nadir AAL was observed in 31 (54.4\%, 31/57) patients. Mostly, it consisted in G1-G2 lymphopenia, with only 4 $(7.0 \%, 4 / 57)$ patients presenting grade 3 or 4 (Fig. 1a). Afterwards, the lymphocyte count kept stable during the 12-months follow-up (Fig. 1b). Considering nadir ARL, 29 $(50.8 \%, 29 / 57)$ patients lost at least $50 \%$ of lymphocytes compared to baseline.

Forty-six $(80.7 \%, 46 / 57)$ patients died during the follow-up. Median OS was 16 months (range 5-55 months),

b

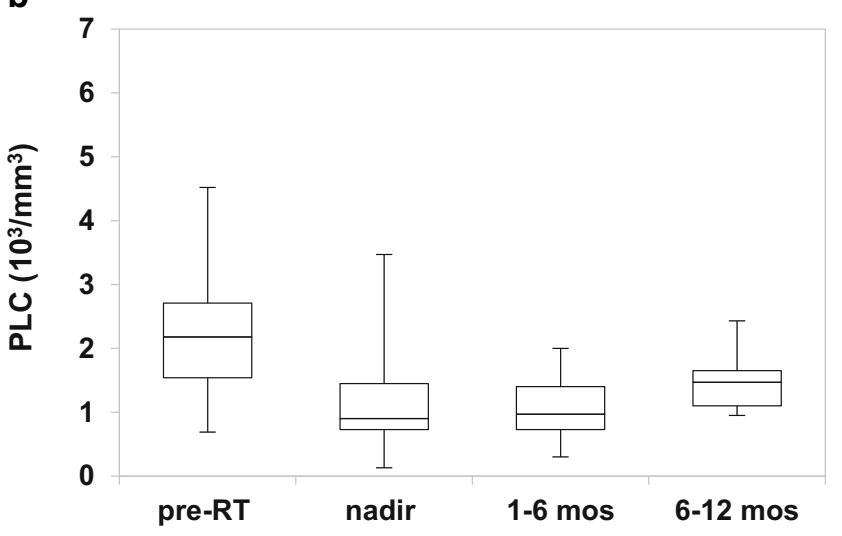

Fig. 1 Lymphocyte count's variation from baseline to nadir, with the onset of acute lymphopenia (a), lymphocyte count's variation from baseline to 1 -year follow-up (b). $R T$ radiotherapy, mos months, $P L C$ peripheral lymphocyte count 

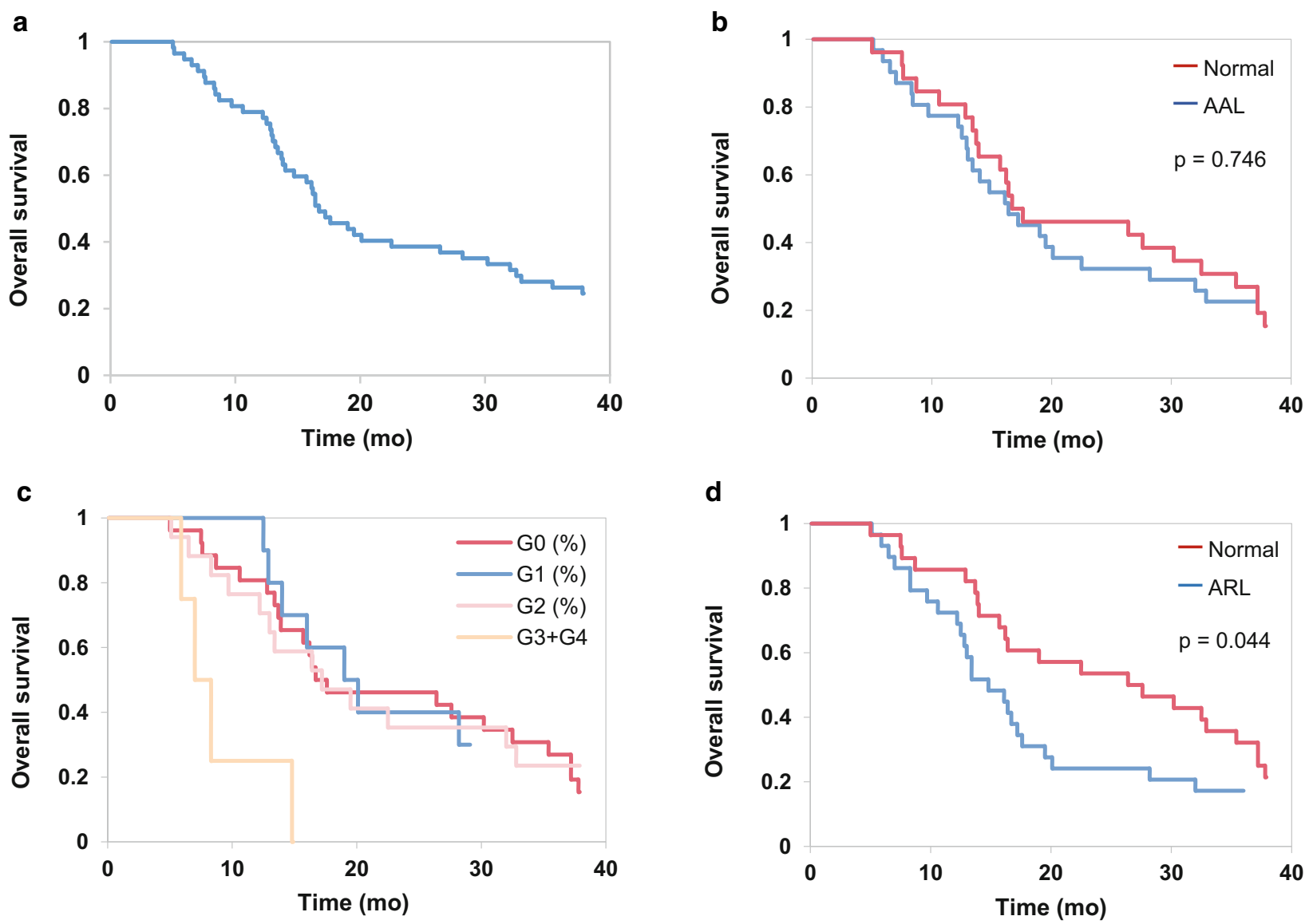

Fig. 2 Kaplan-Meier overall survival curves of the entire group of patients (a), according to the presence of AAL at nadir (b), stratified on grades of $\operatorname{AAL}(p=0.004, \mathbf{c})$ and according to the presence of ARL at nadir $(\mathbf{d})$. Log-rank test, $p$ value $<0.05$. $A A L$ acute absolute lymphopenia, $A R L$ acute relative lymphopenia, mo month, PLC peripheral lymphocyte count, G0 grade 0 (PLC >1000 cells $/ \mathrm{mm}^{3}$ ), G1 grade 1 (PLC: $1000-800 \mathrm{cells} / \mathrm{mm}^{3}$ ), G2 grade 2 (PLC: $800-500$ cells $/ \mathrm{mm}^{3}$ ), G3 grade 3 (PLC: 500-200 cells $/ \mathrm{mm}^{3}$ ), G4 grade 4 (PLC $<200$ cells $/ \mathrm{mm}^{3}$ )

with no significant difference between patients who developed nadir AAL and those who did not (16 months vs 16.5 months; $p$-value 0.304 , respectively). The 18 months OS rate was $45.6 \%(26 / 57)$ for the entire population (Fig. 2a), with no significant difference between the former and the latter group $(45.2 \%, 14 / 31$, vs $46.2 \%$, 12/26; $p$-value: 0.576 , respectively). However, median OS was 14 months vs 26 months ( $p$-value: 0.013) in ARL vs non-ARL groups. Likewise, the 18-months OS rate was $31.0 \%$ (8/29) vs $60.7 \%$ (17/28), respectively ( $p$-value: 0.012 ).

\section{Acute lymphopenia and survival}

Kaplan-Meier curves did not show a significant difference in survival between AAL and non-AAL patients (Fig. 2b). There were no statistical differences in stratified data as well (Fig. 2c), except for patients who developed high-grade lymphopenia (G3+G4 group), whose number was limited (no.: 4). Considering nadir ARL, OS was markedly shorter in patients who lost $>50 \%$ of lymphocytes (Fig. 2d).
In order to investigate clinical and dosimetric factors associated with OS, univariate and multivariate Cox's regressions were performed (Table 2). Some of the most important variables related to survival were included in the analysis. Interruption of concomitant chemotherapy (CT) was considered in order to investigate if the onset of hematological toxicities could have affected OS. MGMT hypermethylation was not added because of lack of data, as indicated in Table 1. Only variables statistically significant at the univariate analysis were included in the multivariate model. Older age, sex (male), subtotal resection of glioblastoma and higher brain D98\% were independently associated with worse OS. Conversely, access to adjuvant CT was related to a better prognosis. Despite reaching statistical significance at univariate analysis, nadir ARL and G3-G4 lymphopenia were not independently associated with OS. The hypothalamic dosimetric factors were not involved in differences in survival. 
Table 2 Cox's regression analysis about clinical and dosimetric variables associated with overall survival

\begin{tabular}{|c|c|c|c|c|}
\hline & $\begin{array}{l}\text { Univariate Cox's regres- } \\
\text { sion }\end{array}$ & & $\begin{array}{l}\text { Multivariate Cox's regres- } \\
\text { sion }\end{array}$ & \\
\hline Variables & $\mathrm{HR}(95 \% \mathrm{CI})$ & $p$-value & $\mathrm{HR}(95 \% \mathrm{CI})$ & $p$-value \\
\hline$\overline{\text { Age }}$ & $1.04(1.01-1.07)$ & $* 0.009$ & $1.06(1.02-1.09)$ & $* 0.003$ \\
\hline Sex (male vs female) & $2.04(1.12-3.70)$ & $* 0.020$ & $3.04(1.50-6.14)$ & $* 0.002$ \\
\hline $\begin{array}{l}\text { Extent of surgery (subtotal resection vs gross total } \\
\text { resection) }\end{array}$ & $2.35(1.19-4.62)$ & $* 0.013$ & $2.47(1.08-5.65)$ & $* 0.032$ \\
\hline Time b/w surgery and $\mathrm{RT} \geq 6$ weeks & $0.79(0.33-1.89)$ & 0.597 & - & - \\
\hline Steroid dose 1-month FUP $\geq 4 \mathrm{mg} /$ day & $1.88(1.03-3.42)$ & $* 0.040$ & $1.01(0.50-2.04)$ & 0.986 \\
\hline KPS pre-RT $\leq 70$ & $2.04(1.10-3.79)$ & $* 0.023$ & $0.58(0.25-1.38)$ & 0.222 \\
\hline Concomitant CT interrupted (yes vs no) & $2.62(0.99-6.94)$ & 0.052 & - & - \\
\hline Adjuvant CT (yes vs no) & $0.10(0.04-0.26)$ & $*<0.001$ & $0.10(0.02-0.52)$ & $* 0.006$ \\
\hline ARL (yes vs no) & $1.82(1.01-3.29)$ & $* 0.050$ & $1.00(0.47-2.13)$ & 0.992 \\
\hline $\begin{array}{l}\text { Lymphocytes at 1-month FUP }<500 \text { (G3-G4 lym- } \\
\text { phopenia) }\end{array}$ & $6.02(2.01-18.02)$ & $* 0.001$ & $0.65(0.13-3.42)$ & 0.615 \\
\hline Radiation technique (VMAT vs 3D-CRT) & $1.09(0.33-3.58)$ & 0.881 & - & - \\
\hline PTV & $1.00(0.99-1.01)$ & 0.288 & - & - \\
\hline Brain Dmean & $1.04(0.99-1.10)$ & 0.137 & - & - \\
\hline Brain D98\% & $1.99(1.15-3.44)$ & $* 0.014$ & $2.63(1.38-5.03)$ & $* 0.003$ \\
\hline Hypothalamus Dmin & $1.01(0.99-1.03)$ & 0.332 & - & - \\
\hline Hypothalamus Dmax & $1.00(0.98-1.02)$ & 0.663 & - & - \\
\hline Hypothalamus Dmean & $1.00(0.99-1.03)$ & 0.538 & - & - \\
\hline
\end{tabular}

$H R$ hazard ratio, $C I$ confidence interval, $b / w$ between, $R T$ radiotherapy, FUP follow-up, KPS Karnofsky performance status, $C T$ chemotherapy, $A R L$ acute relative lymphopenia, $G 3$ grade 3, G4 grade 4,VMAT volumetric modulated arc therapy, $3 D$ - $C R T$ three-dimension conformal radiotherapy, PTV planning target volume, Dmean mean dose, D98\% dose administered to $98 \%$ of volume, Dmin minimal dose, Dmax maximal dose *Variables statistically significant $(p$ value $\leq 0.05$ )

\section{Acute lymphopenia and etiological factors}

Association analyses between nadir AAL and major clinical and dosimetric variables were performed (Online Resource 2). Steroid dose $\geq 4 \mathrm{mg} / \mathrm{day}, \mathrm{CTV}$, PTV, brain V50, brain D2\% were significantly associated with AAL. Smaller doses of dexamethasone and D2\% brain, as well as smaller CTV and PTV volumes and brain V50, turned out to be associated with the development of AAL. All hypothalamic variables failed in reaching statistical significance.

As shown in Table 3, only the interruption of concomitant CT was significantly associated with development of nadir ARL.

\section{Discussion}

During the past decade, scientific evidence has emerged showing that ionizing radiations may have systemic effects converting the tumor into an individualized in situ vaccine sometimes resulting in the so-called abscopal effect, an outof-the-field effect of local RT which can effectively immunize the patient against the irradiated tumor [23, 24]. However, as circulating lymphocyte populations are highly radiosensitive and can undergo apoptosis or depletion due to radiation exposure, this positive impact is often counter- acted by radiation-induced lymphopenia, which suppresses antitumor immunity and is associated with inferior survival in patients with various solid tumors [1-7].

In the present study, we have investigated the correlation between lymphocytes depletion and survival in a cohort of patients with glioblastoma (GBM) who underwent concurrent RT/TMZ and explored possible risk factors for posttreatment acute lymphopenia.

With a median follow up of 16.7 months (I-III quartile: 12.7-28.8 months), median OS was 16 months (5-55 months) and the 18-month OS rate was $45.6 \%$ (Fig. 2a), which largely paralleled the outcomes observed in contemporary series of RT plus concomitant and adjuvant TMZ for GBM [25].

The paired analysis of pre- and posttreatment complete blood counts revealed that patients experienced a substantial reduction in median values of peripheral lymphocyte count (PLC), from 2180 cells $/ \mathrm{mm}^{3}$ at baseline to 900 cells $/ \mathrm{mm}^{3}$ at nadir ( $p$-value $<0.001$ ), in accordance with other studies $[11,16,26]$. Unlike others [11, 26, 27], however, when we looked at a possible impact of such treatment-related lymphopenia, log-rank test failed to identify a correlation between nadir AAL and OS (Fig. 2b). This data might be explained by the low incidence of severe AAL in this cohort. Although a significant lymphocytes depletion occurred at the treatment completion, only a minority of patients $(7.0 \%$, 
Table 3 Clinical, biological and dosimetric factors associated with the development of ARL at nadir

\begin{tabular}{|c|c|c|c|}
\hline Features & ARL & Non-ARL & $p$-value \\
\hline Number of patients & 29 & 28 & - \\
\hline \multicolumn{4}{|l|}{ Clinical characteristics } \\
\hline Sex male $(\%)$ & $16(55.2 \%)$ & $15(53.6 \%)$ & $0.557^{\mathrm{c}}$ \\
\hline $\mathrm{Age}^{\mathrm{a}}$ & $61(58.7-67.0)$ & $60.5(52.3-64.7)$ & $0.237^{\mathrm{d}}$ \\
\hline Macroscopic radical surgery $(\%)$ & $7(24.1 \%)$ & $9(32.1 \%)$ & $0.777^{\mathrm{c}}$ \\
\hline Time b/w surgery and RT $\geq 6$ weeks (\%) & $26(89.7 \%)$ & $23(82.1 \%)$ & $0.333^{\mathrm{c}}$ \\
\hline Steroid dose 1-month FUP $\geq 4$ mg/day (\%) & $15(51.7 \%)$ & $14(50.0 \%)$ & $0.554^{\mathrm{c}}$ \\
\hline CT pre-RT $(\%)$ & $19(65.5 \%)$ & $15(53.6 \%)$ & $0.258^{\mathrm{c}}$ \\
\hline CT/RT concomitant $(\%)$ & $29(100 \%)$ & $28(100 \%)$ & NA \\
\hline Concomitant CT interrupted & $6(20.7 \%)$ & $0(0 \%)$ & $* 0.013^{\mathrm{c}}$ \\
\hline \multicolumn{4}{|l|}{ Pathological characteristics } \\
\hline MGMT: hypermethylated (\%) & $11(57.9 \%)$ & $11(47.8 \%)$ & $0.367^{\mathrm{c}}$ \\
\hline MGMT: non-hypermethylated (\%) & $8(42.1 \%)$ & $12(52.2 \%)$ & - \\
\hline \multicolumn{4}{|l|}{ Dosimetric characteristics } \\
\hline $\operatorname{VMAT}(\%)$ & $3(10.3 \%)$ & $2(7.1 \%)$ & $0.517^{\mathrm{c}}$ \\
\hline $\mathrm{GTV}^{\mathrm{b}}$ & $51.4 \mathrm{~cm}^{3}(41.8-90.0)$ & $69.6 \mathrm{~cm}^{3}(60.9-80.7)$ & $0.394^{\mathrm{d}}$ \\
\hline $\mathrm{CTV}^{\mathrm{b}}$ & $122.1 \mathrm{~cm}^{3}(104.8-154.1)$ & $148.3 \mathrm{~cm}^{3}(130.7-161.4)$ & $0.129^{\mathrm{d}}$ \\
\hline $\mathrm{PTV}^{\mathrm{b}}$ & $198.5 \mathrm{~cm}^{3}(174.0-243.7)$ & $204.8 \mathrm{~cm}^{3}(155.7-223.8)$ & $0.140^{\mathrm{d}}$ \\
\hline \multicolumn{4}{|l|}{$P T V$} \\
\hline Dmean $^{\mathrm{b}}$ & 60.5 Gy $(60.3-60.7)$ & 60.3 Gy $(60.1-60.6)$ & $0.288^{\mathrm{d}}$ \\
\hline D98\% ${ }^{\mathrm{b}}$ & 57.4 Gy (56.5-57.9) & $57.5 \mathrm{~Gy}(56.6-57.8)$ & $0.714^{\mathrm{d}}$ \\
\hline $\mathrm{D} 95 \%{ }^{\mathrm{b}}$ & $58.3 \mathrm{~Gy}(58.0-58.6)$ & $58.1 \mathrm{~Gy}(57.8-58.5)$ & $0.416^{\mathrm{d}}$ \\
\hline \multicolumn{4}{|l|}{$O A R s$} \\
\hline D50\% brainstem ${ }^{\mathrm{b}}$ & 25.3 Gy (17.9-27.3) & 17.5 Gy $(6.8-25.5)$ & $0.170^{\mathrm{d}}$ \\
\hline V50 brainstem ${ }^{\mathrm{b}}$ & $10.6 \%(1.6-15.6)$ & $6.9 \%(0.4-17.0)$ & $0.785^{\mathrm{d}}$ \\
\hline $\mathrm{D} 2 \%$ brainstem $^{\mathrm{b}}$ & 57.1 Gy $(51.8-57.9)$ & $56.3 \mathrm{~Gy}(47.5-58.7)$ & $0.867^{\mathrm{d}}$ \\
\hline $\mathrm{D} 2 \%$ chiasm $^{\mathrm{b}}$ & 39.7 Gy (27.6-53.4) & 23.5 Gy $(8.4-49.2)$ & $0.161^{\mathrm{d}}$ \\
\hline \multicolumn{4}{|l|}{ Brain } \\
\hline $\mathrm{V} 50^{\mathrm{b}}$ & $21.7 \%(17.1-27.1)$ & $24.3 \%(20.3-31.3)$ & $0.135^{\mathrm{d}}$ \\
\hline Dmean $^{b}$ & 25.2 Gy (21.6-27.8) & 24.5 Gy $(23.1-30.1)$ & $0.566^{\mathrm{d}}$ \\
\hline $\mathrm{D} 98 \%^{\mathrm{b}}$ & $1.3 \mathrm{~Gy}(0.9-1.4)$ & $1.0 \mathrm{~Gy}(0.8-1.3)$ & $0.149^{\mathrm{d}}$ \\
\hline $\mathrm{D} 2 \%^{\mathrm{b}}$ & $61.8 \mathrm{~Gy}(61.5-62.1)$ & $61.9 \mathrm{~Gy}(61.7-62.0)$ & $0.844^{\mathrm{d}}$ \\
\hline \multicolumn{4}{|l|}{ Hypothalamus } \\
\hline Volume $^{\mathrm{b}}$ & $7.9 \mathrm{~cm}^{3}(7.1-8.8)$ & $8.7 \mathrm{~cm}^{3}(8.0-10.5)$ & $0.658^{\mathrm{d}}$ \\
\hline D98\% ${ }^{\mathrm{b}}$ & 21.9 Gy (9.8-23.9) & $9.3 \mathrm{~Gy}(4.0-23.8)$ & $0.232^{\mathrm{d}}$ \\
\hline $\mathrm{D} 2 \%^{\mathrm{b}}$ & $53.6 \mathrm{~Gy}(41.0-57.6)$ & $56.2 \mathrm{~Gy}(29.4-58.4)$ & $0.781^{\mathrm{d}}$ \\
\hline $\mathrm{D} 50 \%^{\mathrm{b}}$ & 25.9 Gy $(24.0-33.7)$ & $26.7 \mathrm{~Gy}(14.7-35.9)$ & $0.658^{\mathrm{d}}$ \\
\hline $\operatorname{Dmin}^{\mathrm{b}}$ & 19.6 Gy $(6.0-23.2)$ & $6.3 \mathrm{~Gy}(3.1-21.3)$ & $0.124^{\mathrm{d}}$ \\
\hline $\operatorname{Dmax}^{\mathrm{b}}$ & 57.0 Gy (46.0-58.6) & 58.4 Gy $(46.2-59.5)$ & $0.706^{\mathrm{d}}$ \\
\hline Dmean $^{\mathrm{b}}$ & 27.7 Gy $(23.2-36.8)$ & 29.6 Gy $(19.1-39.0)$ & $0.646^{\mathrm{d}}$ \\
\hline
\end{tabular}

$A R L$ acute relative lymphopenia, $M G M T \mathrm{O}^{6}$-methylguanine-DNA-methyltransferase, $R T$ radiotherapy, $C T$ chemotherapy, $F U P$ follow-up, GTV gross tumor volume, CTV clinical target volume, PTV planning target volume, OARs organs at risk, VMAT volumetric modulated arc therapy, Dmax maximal dose, Dmean mean dose, Dmin minimal dose, D98\% dose administered to $98 \%$ of volume, D95\% dose administered to $95 \%$ of volume, $D 50 \%$ dose administered to $50 \%$ of volume, $D 2 \%$ dose administered to $2 \%$ of volume, $V 50$ volume that received $50 \mathrm{~Gy}, \mathrm{~cm}^{3}$ cubic centimeter, $G y$ gray, $b / w$ between

${ }^{\mathrm{a}}$ Median value (95\% interval of confidence)

${ }^{b}$ Median value (I-III quartile)

'Fisher's exact test

${ }^{\mathrm{d}}$ Wilcoxon sum rank test

*Variables statistically significant ( $p$ value $<0.05$ ) 
4/57) experienced a G3-G4 lymphopenia (Fig. 1a). Therefore, it is unsurprising that a mild nadir AAL did not translate into a significant survival detriment. Conversely, focusing the analysis on nadir ARL, expressed by the nadir-PLC/ baseline-PLC ratio $<0.50$, a statistically significant correlation with OS was found in patients who lost $>50 \%$ of lymphocytes from the baseline ( $p$-value $=0.044$; Fig. $2 d$ ). These findings are similar to those obtained from a post hoc analysis of a randomized controlled trial of postmastectomy hypofractionated radiation therapy [28] and are among the few ones that aimed at the nadir-PLC/baseline-PLC ratio as a potential prognostic factor. Rather than AAL, the use of ARL better conveys the rapid fall off in PLC, which might be associated with poorer outcomes. Failure to complete the concomitant TMZ has emerged as a significant risk factor in the development of nadir ARL, suggesting that chemotherapy-related myelosuppression might have played a role in negatively affecting the nadir-PLC/baseline-PLC ratio.

We also investigated whether nadir ARL and severe AAL could be independently associated with OS. Despite being statistically significant at univariate Cox's regression, both factors were not confirmed to have a prognostic value at multivariate analysis (Table 2). However, older age, gender (male), subtotal resection of glioblastoma and higher brain D98\% were associated with worse OS. Notably, access to adjuvant chemotherapy (CT) after chemoradiation was related to a better prognosis. This finding was consistent with the established knowledge that adjuvant temozolomide significantly increases OS in glioblastoma patients [10]. Despite the interruption of concomitant CT being associated with the development of ARL, it did not affect OS.

As a series of preclinical studies has shown that the hypothalamus (HT) acts as an immunoregulatory center [29, 30] playing a crucial role in the regulation of peripheral immune functions, we have included it among the dosimetric factors that, together with other clinical variables, might have been potentially implied in the development of posttreatment lymphopenia. Unexpectedly, the associations analyses revealed that smaller doses of dexamethasone and brain D2\%, as well as smaller CTV and PTV volumes and brain V50, turned out to be associated with the development of nadir AAL (Online Resource 2). HT dosimetric features (D98\%, D2\%, D50\%, Dmin, Dmax, Dmean) were also not found to be independently associated with the development of treatment-related lymphopenia. These findings are not in keeping with previous studies [11, 16, 26, 31], likely owing to the scarce uniformity in the radiation techniques and volumes, and the relatively small population. However, as in patients with abnormal $\left(<1000\right.$ cell $\left./ \mathrm{mm}^{3}\right)$ posttreatment PLC, the most common tumor locations were the temporal and parietal lobes $(58.1 \%$ in AAL vs $30.8 \%$ in nonAAL), both supplied by the middle cerebral artery, it is conceivable that the irradiation of brain areas supplied by the largest branch of the internal carotid [32] might have resulted in a more relevant PLC depletion, thus overcoming the effect of other factors.

Radiation-induced lymphopenia is commonly correlated with lower dose ranges [3, 22] because of the high radiosensitivity of lymphocytes. Commercially available TPS are usually not designed to model dose distribution of very small doses due to computational requirements and little relevance for routine treatment planning. The accuracy of calculated out-of-field doses receives less attention because they are significantly lower compared to the prescribed target dose. Several investigations have previously been devoted to the study of the out-of-field doses [33-38]. The conclusions varied widely and depended upon the treatment modalities and anatomical location of target volumes, but poor accuracy and larger underestimation of out-field dose calculations were generally highlighted. Accordingly, small doses that could affect lymphopenia may not be calculated properly using the clinical TPS. For these reasons, they were overlooked in our study. However, it cannot be excluded that the exposure of healthy tissue to integral wholebody doses, an established dosimetric factor which differentiates the dose delivery methods [39] might play a role in the iatrogenic lymphopenia, thus explaining the contradictory findings of reduced lymphopenia with smaller treatment volumes.

Beyond its intrinsic retrospective nature, our study has further limitations: we did not consider that, apart from direct toxicity, RT might have indirectly affected PLC by means of cytokine modulation [40]. For example, interleukin-7 (IL-7), a cytokine involved in T-cell proliferation, is well recognized to play a pivotal role in maintaining circulating T-cell homeostasis. Furthermore, we have considered PLC as a whole entity, without discriminating different lymphocyte subpopulations that might exert their effector mechanisms after RT at different levels [41]. Finally, although MGMT-methylation status is nowadays an established prognostic factor, we could not evaluate it because it was not systematically included in the pathological assessment of resected GBM, especially in patients treated before 2017 .

In conclusion, despite the evidence that immunosuppression induced by CT-RT (concomitant chemo-radiotherapy) is associated with inferior clinical outcomes, our data show that treatment-related lymphopenia does not adversely affect the prognosis in patients with GBM treated with RT/TMZ.

The use of ARL coupled with AAL is merely hypothesis-generating and must be proven in a confirmatory study. Nevertheless, an improved understanding of the biology behind AAL/ARL might help to prevent inadvertent lymphocyte depletion or to restore lymphocytes during or after CTRT. 
Supplementary Information The online version of this article (https:// doi.org/10.1007/s00066-021-01855-5) contains supplementary material, which is available to authorized users.

Acknowledgements The authors would like to express their gratitude to Dr. Linda Agolli (Medizinischen Versorgungszentren (MVZ) und Praxen in Nordrhein-Westfalen für Strahlentherapie) for translating the abstract in German.

Funding Open access funding provided by Università degli Studi di Milano - Bicocca within the CRUI-CARE Agreement.

\section{Declarations}

Conflict of interest R. Mapelli, C. Julita, S. P. Bianchi, N. Gallina, R. Lucchini, M. Midulla, F. Puci, J. Saddi, S. Trivellato, D. Panizza, E. De Ponti and S. Arcangeli declare that they have no competing interests.

Ethical standards All procedures performed in studies involving human participants or on human tissue were in accordance with the ethical standards of the institutional (Review Board of University of Milan-Bicocca) and/or national research committee and with the 1975 Helsinki declaration and its later amendments or comparable ethical standards. Informed consent was obtained from all individual participants included in the study.

Open Access This article is licensed under a Creative Commons Attribution 4.0 International License, which permits use, sharing, adaptation, distribution and reproduction in any medium or format, as long as you give appropriate credit to the original author(s) and the source, provide a link to the Creative Commons licence, and indicate if changes were made. The images or other third party material in this article are included in the article's Creative Commons licence, unless indicated otherwise in a credit line to the material. If material is not included in the article's Creative Commons licence and your intended use is not permitted by statutory regulation or exceeds the permitted use, you will need to obtain permission directly from the copyright holder. To view a copy of this licence, visit http://creativecommons.org/licenses/by/4. $0 /$.

\section{References}

1. Shiraishi Y, Fang P, Xu C, Song J, Krishnan S, Koay EJ, Mehran RJ, Hofstetter WL, Blum-Murphy M, Ajani JA, Komaki R, Minsky B, Mohan R, Hsu CC, Hobbs BP, Lin SH (2018) Severe lymphopenia during neoadjuvant chemoradiation for esophageal cancer: a propensity matched analysis of the relative risk of proton versus photon-based radiation therapy. Radiother Oncol 128(1):154-160

2. Campian JL, Ye X, Brock M, Grossman SA (2013) Treatment-related lymphopenia in patients with stage III non-small-cell lung cancer. Cancer Invest 31(3):183-188

3. Tang C, Liao Z, Gomez D, Levy L, Zhuang Y, Gebremichael RA, Hong DS, Komaki R, Welsh JW (2014) Lymphopenia association with gross tumor volume and lung V5 and its effects on non-small cell lung cancer patient outcomes. Int J Radiat Oncol Biol Phys 89(5):1084-1091

4. Cho O, Oh YT, Chun M, Noh OK, Lee HW (2016) Radiation-related lymphopenia as a new prognostic factor in limited-stage small cell lung cancer. Tumour Biol 37(1):971-978

5. Wild AT, Ye X, Ellsworth SG, Smith JA, Narang AK, Garg T, Campian J, Laheru DA, Zheng L, Wolfgang CL, Tran PT, Grossman SA, Herman JM (2015) The association between chemoradiation-related lymphopenia and clinical outcomes in patients with locally advanced pancreatic adenocarcinoma. Am J Clin Oncol 38(3):259-265

6. Wu ES, Oduyebo T, Cobb LP, Cholakian D, Kong X, Fader AN, Levinson KL, Tanner EJ 3rd, Stone RL, Piotrowski A, Grossman S, Roche KL (2016) Lymphopenia and its association with survival in patients with locally advanced cervical cancer. Gynecol Oncol 140(1):76-82

7. Cho O, Chun M, Chang SJ, Oh YT, Noh OK (2016) Prognostic value of severe lymphopenia during pelvic concurrent chemoradiotherapy in cervical cancer. Anticancer Res 36(7):3541-3547

8. Trowell OA (1952) The sensitivity of lymphocytes to ionising radiation. J Pathol Bacteriol 64(4):687-704

9. Nakamura N, Kusunoki Y, Akiyama M (1990) Radiosensitivity of CD4 or CD8 positive human T-lymphocytes by an in vitro colony formation assay. Radiat Res 123(2):224-227

10. Stupp R, Mason WP, van den Bent MJ, Weller M, Fisher B et al (2005) Radiotherapy plus concomitant and adjuvant temozolomide for glioblastoma. N Engl J Med 352(10):987-996

11. Grossman SA, Ye X, Lesser G, Sloan A, Carraway H, Desideri S, Piantadosi S (2011) Immunosuppression in patients with highgrade gliomas treated with radiation and temozolomide. Clin Cancer Res 17(16):5473-5480

12. Yu SK, Chalmers AJ (2007) Patients receiving standard-dose temozolomide therapy are at risk of Pneumocystis carinii pneumonia. Clin Oncol (R Coll Radiol) 19:631-632

13. Schwarzberg AB, Stover EH, Sengupta T et al (2007) Selective lymphopenia and opportunistic infections in neuroendocrine tumor patients receiving temozolomide. Cancer Invest 25:249-255

14. Yaman E, Coskun U, Ozturk B et al (2009) Opportunistic cytomegalovirus infection in a patient receiving temozolomide for treatment of malignant glioma. J Clin Neurosci 16:591-592

15. De Jesus A, Grossman SA, Paun O (2009) Cytomegalovirus associated colonic pseudotumor: a consequence of iatrogenic immunosuppression in a patient with primary brain tumor receiving radiation and temozolomide. J Neurooncol 94:445-448

16. Yovino S, Kleinberg L, Grossman SA, Narayanan M, Ford E (2013) The etiology of treatment-related lymphopenia in patients with malignant gliomas: modeling radiation dose to circulating lymphocytes explains clinical observations and suggests methods of modifying the impact of radiation on immune cells. Cancer Invest 31(2):140-144

17. Finocchiaro G, Pellegatta S (2014) Perspectives for immunotherapy in glioblastoma treatment. Curr Opin Oncol 26(6):608-614. https:// doi.org/10.1097/CCO.0000000000000135

18. Reardon DA, Freeman G, Wu C, Chiocca EA, Wucherpfennig KW, Wen PY, Fritsch EF, Curry WT Jr, Sampson JH, Dranoff G (2014) Immunotherapy advances for glioblastoma. Neuro Oncol 16(11):1441-1458

19. Gupta T, Mohanty S, Moiyadi A, Jalali R (2013) Factors predicting temozolomide induced clinically significant acute hematologic toxicity in patients with high-grade gliomas: a clinical audit. Clin Neurol Neurosurg 115(9):1814-1819

20. Hughes MA, Parisi M, Grossman S, Kleinberg L (2005) Primary brain tumors treated with steroids and radiotherapy: low CD4 counts and risk of infection. Int J Radiat Oncol Biol Phys 62(5): $1423-1426$

21. Ishikawa E, Yamamoto $T$, Sakamoto N, Nakai K, Akutsu H, Tsuboi K, Takano S, Matsumura A (2010) Low peripheral lymphocyte count before focal radiotherapy plus concomitant temozolomide predicts severe lymphopenia during malignant glioma treatment. Neurol Med Chir (Tokyo) 50(8):638-644

22. Cabrera AR, Kirkpatrick JP, Fiveash JB et al (2016) Radiation therapy for glioblastoma: executive summary of an American Society for Radiation Oncology evidence-based clinical practice guideline. Pract Radiat Oncol 6(4):217-225 
23. Demaria S, Ng B, Devitt ML, Babb JS, Kawashima N, Liebes L, Formenti SC (2004) Ionizing radiation inhibition of distant untreated tumors (abscopal effect) is immune mediated. Int J Radiat Oncol Biol Phys 58(3):862-870

24. Golden EB, Chachoua A, Fenton-Kerimian MB et al (2015) Abscopal responses in metastatic non-small cell lung cancer (NSCLC) patients treated on a phase 2 study of combined radiation therapy and ipilimumab: evidence for the in situ vaccination hypothesis of radiation. Int J Radiat Oncol Biol Phys 93:S66-S67

25. Koshy M, Villano JL, Dolecek TA, Howard A, Mahmood U, Chmura SJ, Weichselbaum RR, McCarthy BJ (2012) Improved survival time trends of glioblastoma using the SEER 17 population-based registries. J Neurooncol 107(1):207-212

26. Ye LL, Fan XW, Hu CS, He XY, Wang XS, Shen CY, Xu TT, Ying HM (2019) Dosimetry of the brain and hypothalamus predicting acute lymphopenia and the survival of glioma patients with postoperative radiotherapy. Cancer Med 8(6):2759-2768

27. Mendez JS, Govindan A, Leong J, Gao F, Huang J, Campian JL (2016) Association between treatment-related lymphopenia and overall survival in elderly patients with newly diagnosed glioblastoma. J Neurooncol 127(2):329-335

28. Sun GY, Wang SL, Song YW, Jin J, Wang WH, Liu YP, Ren H, Fang H, Tang Y, Zhao XR, Song YC, Yu ZH, Liu XF, Li YX (2020) Radiation-induced lymphopenia predicts poorer prognosis in patients with breast cancer: a post hoc analysis of a randomized controlled trial of postmastectomy hypofractionated radiation therapy. Int J Radiat Oncol Biol Phys 108(1):277-285

29. Baciu I, Hriscu M, Saulea G (2003) Hypothalamic mechanisms of immunity. Int J Neurosci 113(2):259-277

30. Pavlov VA, Tracey KJ (2017) Neural regulation of immunity: molecular mechanisms and clinical translation. Nat Neurosci 20(2):156-166

31. Huang J, DeWees T, Badiyan SN, Speirs CK, Mullen DF, Fergus S, Tran DD, Linette G, Campian JL, Chicoine MR, Kim AH, Dunn G, Simpson JR, Robinson CG (2015) Clinical and dosimetric predictors of acute severe lymphopenia during radiation therapy and concurrent temozolomide for high-grade glioma. Int J Radiat Oncol Biol Phys 92(5):1000-1007
32. Zarrinkoob L, Ambarki K, Wåhlin A, Birgander R, Eklund A, Malm J (2015) Blood flow distribution in cerebral arteries. J Cereb Blood Flow Metab 35(4):648-654

33. Howell RM, Scarboro SB, Kry SF, Yaldo DZ (2010) Accuracy of out-of-field dose calculations by a commercial treatment planning system. Phys Med Biol 55(23):6999-7008

34. Howell RM, Scarboro SB, Taddei PJ, Krishnan S, Kry SF, Newhauser WD (2010) Methodology for determining doses to in-field, out-of-field and partially in-field organs for late effects studies in photon radiotherapy. Phys Med Biol 55(23):7009-7023

35. Kaderka R, Schardt D, Durante M, Berger T, Ramm U, Licher J, La Tessa C (2012) Out-of-field dose measurements in a water phantom using different radiotherapy modalities. Phys Med Biol 57:5059-5074

36. Huang JY, Followill DS, Wang XA, Kry SF (2013) Accuracy and sources of error of out-of field dose calculations by a commercial treatment planning system for intensity-modulated radiation therapy treatments. J Appl Clin Med Phys 14(2):4139

37. Ojala JJ, Kapanen MK, Hyödynmaa SJ, Wigren TK, Pitkänen MA (2014) Performance of dose calculation algorithms from three generations in lung SBRT: comparison with full Monte Carlo-based dose distributions. J Appl Clin Med Phys 15(2):4662

38. Covington EL, Ritter TA, Moran JM, Owrangi AM, Prisciandaro JI (2016) Technical Report: Evaluation of peripheral dose for flattening filter free photon beams. Med Phys 43(8):4789

39. Ślosarek K, Osewski W, Grządziel A et al (2015) Integral dose: comparison between four techniques for prostate radiotherapy. Rep Pract Oncol Radiother 20(2):99-103

40. Kondrack RM, Harbertson J, Tan JT, McBreen ME, Surh CD, Bradley LM (2003) Interleukin 7 regulates the survival and generation of memory CD4 cells. J Exp Med 198(12):1797-1806

41. Lee Y, Auh SL, Wang Y, Burnette B, Wang Y, Meng Y, Beckett M, Sharma R, Chin R, Tu T, Weichselbaum RR, Fu YX (2009) Therapeutic effects of ablative radiation on local tumor require CD8+ T cells: changing strategies for cancer treatment. Blood 114(3):589-595 